\title{
Optimalisasi Self Care Management Diabetes pada Pasien Diabetes Mellitus di Puskesmas Parangloe Kabupaten Gowa
}

\author{
Optimization of Diabetes Self Care Management in Diabetes Mellitus Patients at Parangloe \\ Health Center, Gowa Regency
}

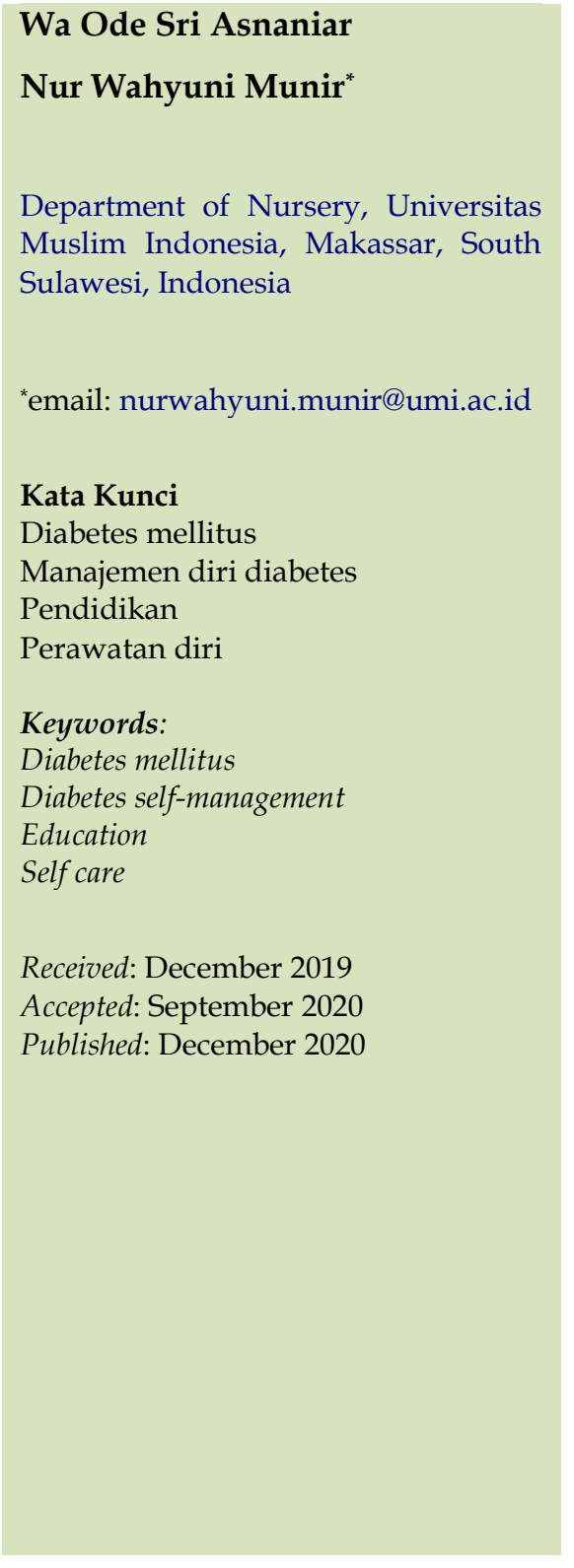

\begin{abstract}
Abstrak
Penatalaksanaan Diabetes Mellitus (DM) bertujuan untuk meningkatkan kualitas hidup penderita DM dan mengurangi risiko komplikasi akut. Diabetes Self-Management Education (DSME) adalah proses yang memfasilitasi pengetahuan, keterampilan, dan kemampuan dalam selfcare pasien DM berdasarkan Evidence-Based Research. Kegiatan ini bertujuan untuk meningkatkan pengetahuan dan derajat kesehatan penderita DM di Puskesmas Parangloe Kabupaten Gowa Sulawesi Selatan. Metode yang digunakan, yaitu ceramah, diskusi, dan demonstrasi. Pemberian DSME dilakukan sebanyak tiga sesi dengan durasi 45 menit dan juga dilakukan pelatihan senam kaki diabetik. Selain itu, dilakukan pemeriksaan kadar gula darah sewaktu. Hasil yang dicapai yaitu peningkatan pengetahuan penderita DM sebesar $63,4 \%$ tentang definisi, klasifikasi, tanda dan gejala, faktor risiko, komplikasi DM, diet, latihan jasmani, jenis dan manfaat obat yang diberikan, perawatan kaki, serta 96\% mampu melakukan senam kaki diabetik. Selain itu, terjadi peningkatan pemahaman dan keterampilan kader tentang self-care management DM. Pasien DM juga diharapkan dapat melakukan pemeriksaan glukosa darah secara teratur dan menggunakan buku Panduan Perawatan Mandiri DM yang telah diberikan.
\end{abstract}

\begin{abstract}
Management of Diabetes Mellitus (DM) aims to improve the quality of life for DM sufferers and reduce the risk of acute complications. Diabetes SelfManagement Education (DSME) is a process that facilitates knowledge, skills, and abilities in self-care for DM patients based on evidence-based research. This activity aims to increase DM sufferers' knowledge and health status at Parangloe Health Center, Gowa Regency, South Sulawesi. The methods used are lectures, discussions, and demonstrations. The DSME administration was carried out in three sessions with 45 minutes and carried out diabetic foot gym training. Besides, the blood sugar level is checked at any time. The results achieved were an increase in knowledge of DM sufferers by $63.4 \%$ regarding definitions, classifications, signs and symptoms, risk factors, DM complications, diet, physical exercise, types and benefits of drugs given, foot care, and $96 \%$ being able to do foot exercises for diabetic. Also, there was an increase in the understanding and skills of cadres about DM self-care management. DM patients are also expected to check their blood glucose regularly and use the DM Self-Care Manual that has been provided.
\end{abstract} Universitas Muhammadiyah Palangkaraya. This is Open Access article under the CC-BY-SA License (http://creativecommons.org/licenses/by-sa/4.0/). DOI: https://doi.org/10.33084/pengabdianmu.v6i1.1156

\section{PENDAHULUAN}

Diabetes Mellitus (DM) adalah penyakit kronis multisistem yang berhubungan dengan produksi insulin yang abnormal, gangguan penggunaan insulin, atau keduanya (Galicia-Garcia et al., 2020). Data WHO pada Tahun 2018 menunjukkan sebanyak 422 juta orang dewasa mengalami DM dan sebanyak 1,6 juta 
meninggal karena DM setiap tahunnya. Adapun di Indonesia, prevalensi DM sebesar 6,7\% (10.276.100 kasus DM dari 166.531 .000 orang dewasa) (International Diabetes Federation, 2018). Provinsi Sulawesi Selatan mengalami kenaikan prevalensi DM berdasarkan diagnosis dokter pada penduduk umur $\geq 15$ tahun sejak tahun 2013 (Kementerian Kesehatan Republik Indonesia, 2018). Adapun pasien DM yang tercatat di Wilayah Kerja Puskesmas Parangloe pada 3 bulan terakhir sebanyak 75 orang.

Penatalaksanaan DM bertujuan untuk meningkatkan kualitas hidup penderita DM dan mengurangi risiko komplikasi akut, seperti ulkus kaki diabetikum sehingga diperlukan perawatan kaki yang tepat (Perkumpulan Endokrinologi Indonesia, 2015). Diabetes Self-Management Education (DSME) adalah proses yang memfasilitasi pengetahuan, keterampilan, dan kemampuan dalam self-care pasien DM berdasarkan Evidence-Based Research (Powers et al., 2016). DSME yang berkualitas akan meningkatkan kualitas hidup, kontrol glukosa darah, manajemen diri pasien, meningkatkan self-efficacy, kepuasan, perilaku self-care, dan menurunkan biaya perawatan kesehatan (Gucciardi et al., 2013; Tang et al., 2013; Cooke et al., 2013; Sugiyama et al., 2015; Hermanns et al., 2015; American Diabetes Association, 2016).

Wawancara dilakukan sebelum senam PROLANIS (Program Pengelolaan Penyakit Kronis) berlangsung sehingga tim yang hanya terdiri dari empat orang hanya dapat mewawancarai 10 orang pasien DM tipe 2 sekitar $30 \%$ pasien yang aktif hadir mengikuti senam tiap minggunya) di Wilayah Kerja Puskesmas Parangloe Kabupaten Gowa, dapat disimpukan bahwa pengetahuan penderita DM masih kurang terkait diet, jenis dan manfaat obat yang diberikan, perawatan kaki, serta komplikasi DM seperti neuropati. Selain itu, tidak dilakukan monitoring glukosa darah secara teratur. Oleh karena itu, penderita DM masih memerlukan edukasi terkait penyakitnya. Program pengabdian kepada masyarakat ini bertujuan untuk meningkatkan pengetahuan dan derajat kesehatan penderita DM di Puskesmas Parangloe Kabupaten Gowa.

\section{METODOLOGI}

Metode yang digunakan, yaitu ceramah, diskusi, dan demonstrasi. Adapun peserta sebanyak 30 orang, yang terdiri dari 25 penderita DM dan 5 kader DM serta didampingi oleh dua orang petugas puskesmas. Selain itu, Sebagian besar peserta merupakan peserta PROLANIS. Pemberian DSME dilakukan sebanyak 3 sesi dengan durasi 45 menit. Lokasi kegiatan di aula Puskesmas Parangloe pada tanggal 16 Oktober 2019. Pemeriksaan glukosa darah sewaktu dilakukan oleh tim pada setiap peserta setelah kegiatan senam PROLANIS di puskesmas menggunakan alat glucometer. Pre-test dilakukan sebelum sesi I dimulai. Pada Sesi I, diberikan pengetahuan dasar tentang konsep DM seperti definisi, klasifikasi, tanda dan gejala, faktor risiko, komplikasi DM. Selain itu juga dijelaskan tentang monitoring kadar glukosa darah. Sesi II berisi penjelasan tentang diet dan perawatan kaki. Adapun Sesi III terkait latihan jasmani dan medikasi. Pada akhir sesi dilakukan demonstrasi senam kaki diabetik dan selanjutnya dilakukan post-test.

\section{HASIL DAN PEMBAHASAN}

Diabetes Self Management Education

Peningkatan pengetahuan dan keterampilan peserta tentang diabetes mellitus dilakukan dengan pemberian penyuluhan kesehatan terkaitPerawatan Mandiri Pasien Diabetes Melitus. Kegiatan dibuka oleh staf Puskesmas Ns. Jumiati selaku penanggung jawab kegiatan PROLANIS pasien diabetes mellitus di Puskesmas Parangloe. Strategi yang digunakan dalam pelatihan/penyuluhan ini yaitu ceramah, dan diskusi. 
Pemberian penyuluhan kesehatan dibagi menjadi 3 sesi. Masing-masing sesi dilakukan selama 15 menit. Mengawali sesi, kami memperkenalkan diri kepada peserta, melakukan kontrak waktu serta menyampaikan tujuan yang ingin dicapai dari pelatihan ini. Sebelum kegiatan dimulai, diawali dengan pre test untuk mengukur pengetahuan peserta tentang materi yang akan kami sampaikan. Dari30 peserta, pengetahuan baik sebanyak 23,3\% dan kurang sebanyak 76,7\%. Selanjutnya, kami menyampaikan perilaku sehat yang dapat dilakukan oleh penyandang DM yang termuat dalam buku Panduan Perawatan Mandiri Diabetes Melitus yang telah kami susun dan bagikan ke peserta. Selain itu, kami menyampaikan bagaimana perspektif Islam tentang penyakit diabetes mellitus.

Sesi 1 dibawakan oleh Ns. Nur Wahyuni Munir tentang perilaku sehat penyandang DM, mengenal DM, klasifikasi DM, gejala DM, faktor risiko, komplikasi, dan diet pada DM. Kemudian dilanjutkan dengan Sesi II tentang monitoring kadar gula darah dan pengobatan yang dilakukan pasien diabetes mellitus. Sesi III dibawakan oleh Ns Wa Ode Sri Asnaniar selaku ketua pelaksana, tentang latihan jasmani pasien diabetes mellitus, perawatan kaki. Dokumentasi disajikan pada Gambar 1, sedangkan hasil tes pada Tabel I.

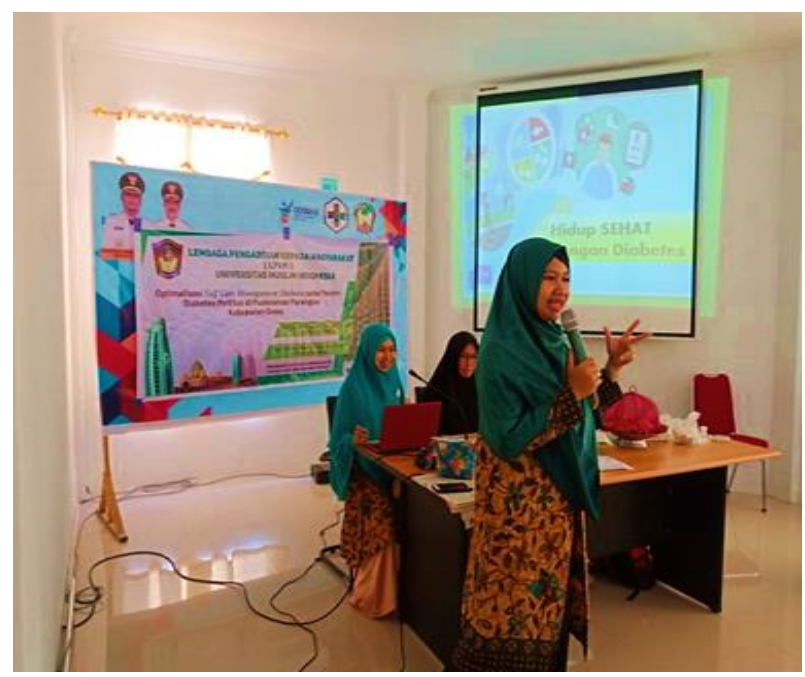

Gambar 1. Penyuluhan Kesehatan tentang Diabetes Melitus
Tabel I. Distribusi pengetahuan peserta tentang diabetes melitus sebelum dan sesudah penyuluhan kesehatan

\begin{tabular}{lrrrr}
\hline \multirow{2}{*}{ Pengetahuan } & \multicolumn{2}{c}{ Pre Test } & \multicolumn{2}{c}{ Post Test } \\
\cline { 2 - 5 } & $\mathbf{n}$ & $\boldsymbol{0}$ & $\mathbf{n}$ & \multicolumn{1}{c}{$\%$} \\
\hline Baik & 7 & 23.33 & 26 & 86.67 \\
Kurang & 23 & 76.67 & 4 & 13.33 \\
\hline Jumlah & 30 & 100 & 30 & 100 \\
\hline
\end{tabular}

Setelah dilakukan penyuluhan kesehatan, pengetahuan peserta tentang DM meningkat menjadi $86,67 \%$ dan pengetahuan yang kurang menurun menjadi 13,3\%. Hasil yang dicapai dari kegiatan ini yaitu terjadi peningkatan pengetahuan peserta tentang DM. Pihak Puskesmas pun meminta agar materi penyuluhan dapat diberikan untuk disampaikan kembali di penyuluhan kesehatan berikutnya yang dilakukan oleh Pihak Puskesmas.

\section{Senam Kaki Diabetik}

Senam kaki diabetik adalah salah satu latihan jasmani untuk pasien diabetes mellitus yang dapat melancarkan peredaran darah pada kaki untuk menghindari terjadinya neuropati pada kaki dan mencegah terjadinya komplikasi berupa ulkus kaki diabetik. Sebelum melakukan latihan senam kaki diabetik, dilakukan pre test pada peserta. Hasilnya menunjukkan $100 \%$ peserta tidak mengetahui tentang senam kaki diabetik. Strategi yang digunakan dalam pelatihan/penyuluhan ini yaitu ceramah, diskusi, demonstrasi dan pendampingan.

Setelah menyampaikan materi tentang senam kaki diabetik, kami mendemonstrasikan cara melakukan senam kaki diabetik dan secara bersamaan dilakukan langsung oleh masing-masing peserta. Senam kaki dilakukan dalam posisi duduk dan pada bagian tertentu menggunakan koran. Senam kaki dilakukan oleh seluruh peserta dan didampingi oleh mahasiswa selaku fasilitator sebagaimana ditunjukkan pada Gambar 2. 


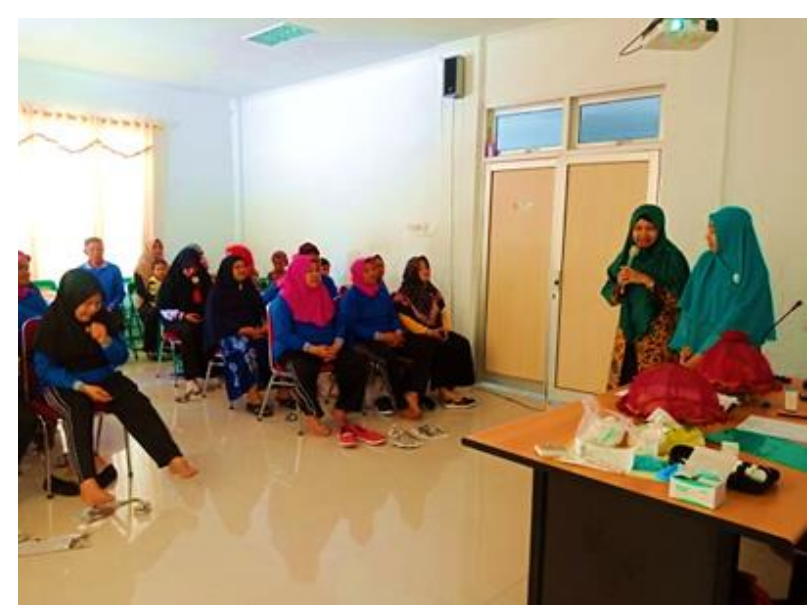

Gambar 2. Latihan Senam Kaki Diabetik

Peserta antusias dan bersemangat melakukan senam kaki karena merupakan hal yang baru dilakukan. Hasil yang diharapkan setelah kegiatan ini yaitu terdapat peningkatan pengetahuan dan keterampilan peserta dalam melakukan senam kaki diabetik. Senam kaki diabetik ini mudah dilakukan dan koran sebagai media yang digunakan juga mudah didapatkan. Hasil yang didapatkan yaitu terjadi peningkatan pengetahuan dan keterampilan peserta tentang senam kaki diabetik yaitu dari $0 \%$ menjadi $96 \%$ (29 dari 30 peserta) dapat melakukan dengan baik. Pihak Puskesmas pun memberi dukungan positif terhadap pengetahuan keterampilan yang kami berikan ke peserta. Untuk menjaga keberlanjutkan senam kaki diabetik tetap dilakukan oleh peserta dirumah, kami memberikan booklet Buku Panduan Perawatan Mandiri Diabetes Melitus kepada peserta baik kader maupun pasien serta kepada pihak Puskesmas Parangloe.

\section{Pemeriksaan Kadar Glukosa Darah}

Selain senam kaki diabetik, kami juga melakukan pemeriksaan kadar gula darah sewaktu pada peserta. Untuk mengukur kadar gula darah peserta, dilakukan pengukuran kadar gula darah pada pembuluh darah perifer di jari pasien secara langsung dengan menggunakan alat pengukuran gula darah Nesco dengan Nesco strip dan kapas alkohol steril.
Pemeriksaan ini dilakukan oleh Ns Wa OdeSri Asnaniar dan dibantu oleh fasilitator serta staf PKM Parangloe yang ditunjukkan pada Gambar 3. Hasil Pemeriksaan kadar glukosa darah disajikan pada Tabel II.

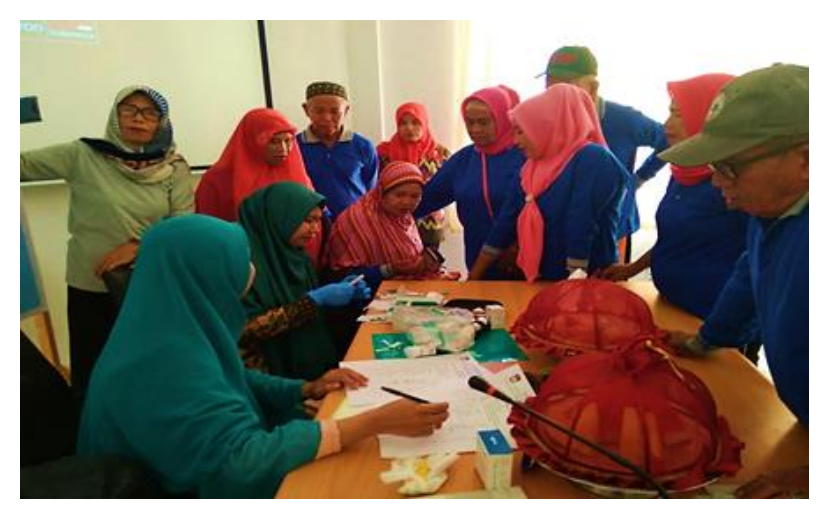

Gambar 3. Pemeriksaan Kadar Gula Darah Sewaktu

Tabel II. Kadar glukosa darah sewaktu dan puasa sebagai patokan penyaring dan diagnosis DM (mg/dl) (Perkumpulan Endokrinologi Indonesia, 2015)

\begin{tabular}{|c|c|c|c|c|}
\hline $\begin{array}{c}\text { Kadar } \\
\text { Glukosa }\end{array}$ & Sampel & $\begin{array}{c}\text { Bukan } \\
\text { DM }\end{array}$ & $\begin{array}{c}\text { Belum pasti } \\
\text { DM }\end{array}$ & DM \\
\hline $\begin{array}{l}\text { Kadar } \\
\text { glukosa }\end{array}$ & $\begin{array}{l}\text { Plasma } \\
\text { Vena }\end{array}$ & $<100$ & $100-199$ & $\geq 200$ \\
\hline $\begin{array}{l}\text { darah } \\
\text { sewaktu } \\
(\mathrm{mg} / \mathrm{dl})\end{array}$ & $\begin{array}{l}\text { Darah } \\
\text { Kapiler }\end{array}$ & $<90$ & $90-199$ & $\geq 200$ \\
\hline $\begin{array}{l}\text { Kadar } \\
\text { glukosa }\end{array}$ & $\begin{array}{l}\text { Plasma } \\
\text { Vena }\end{array}$ & $<100$ & $100-125$ & $\geq 126$ \\
\hline $\begin{array}{l}\text { darah } \\
\text { puasa } \\
(\mathrm{mg} / \mathrm{dl})\end{array}$ & $\begin{array}{l}\text { Darah } \\
\text { Kapiler }\end{array}$ & $<90$ & $90-99$ & $\geq 100$ \\
\hline
\end{tabular}

Dari hasil pemeriksaan kadar gula darah sewaktu peserta pelatihan berdasarkan Tabel II diatas, dapat disimpulkan pada Tabel III berikut:

Tabel III. Distribusi Peserta Berdasarkan Kadar Gula Darah Sewaktu Pada Penderita DM Di Puskesmas Parangloe

\begin{tabular}{llr}
\hline \multicolumn{1}{c}{ Kadar Gula Darah Sewaktu (GDS) } & n & \multicolumn{1}{c}{$\%$} \\
\hline Terkontrol & 17 & 56.67 \\
Tidak terkontrol & 13 & 43.33 \\
\hline Jumlah & $\mathbf{3 0}$ & $\mathbf{1 0 0}$ \\
\hline
\end{tabular}

Berdasarkan Tabel III di atas tentang distribusi peserta berdasarkan kadar gula darah sewaktu menunjukkan bahwa dari 30 peserta masih ada 13 peserta yang memiliki kadar gula tidak terkontrol. Dari hasil tersebut, kami memotivasi peserta yang memiliki kadar gula darah terkontrol untuk tetap mempertahankan pola 
hidupnya dan tetap monitoring kadar gula darahnya, sedangkan untuk peserta yang memiliki kadar gula tidak terkontrol, untuk meningkatkan lagi pola hidup sehat, dengan mengatur pola makan dan melakukan latihan jasmani seperti jalan kaki/jogging, bersepeda, atau berenang serta selalu rutin melakukan pengecekan kadar gula darah di Puskesmas Parangloe.

Pengecekan kadar gula darah berjalan dengan baik dan kooperatif. Peserta antusias ingin mengetahui kadar gula darahnya. Kami menjelaskan hasil dan interpretasi hasil dari pengecekan kadar gula darah peserta. Manfaat dari kegiatan ini, peserta mengetahui kadar gula darahnya dan dapat melakukan tindakan pemeliharaan status kesehatan terhadap interpretasi hasil kadar gula darah.

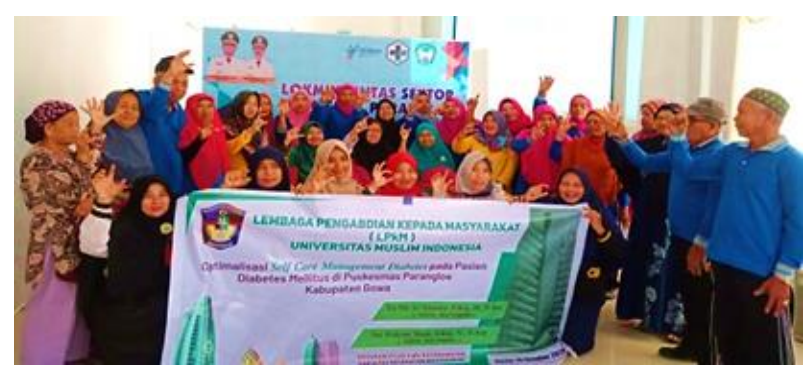

Gambar 4. Foto bersama peserta

\section{KESIMPULAN}

Evaluasi kegiatan pelaksanaan Diabetes Self Management Education (DSME) dilakukan dengan konsistensi peserta dalam mengikuti pelatihan berdasarkan daftar hadir peserta. Evaluasi kegiatan juga dilakukan dengan melihat adanya peningkatan pengetahuan peserta sebesar $63,4 \%$ yang dinilai berdasarkan kemampuan peserta menjawab pertanyaan dari pemateri serta adanya $96 \%$ peningkatan keterampilan dalam melakukan senam kaki diabetik yang dinilai dengan peserta telah mampu melakukan senam kaki diabetik sesuai dengan yang didemonstrasikan oleh pemateri. Pihak Puskesmas dan kader diharapkan dapat melakukan pendataan dan motivasi kepada pasien DM yang belum tergabung dalam Program Pengelolaan Penyakit Kronis (PROLANIS) serta melakukan penyuluhan kesehatan secara rutin kepada pasien DM berdasarkan buku Panduan Perawatan Mandiri DM yang telah diberikan untuk peningkatan self-care management pasien DM di Puskesmas Parangloe.

\section{UCAPAN TERIMA KASIH}

Penulis mengucapkan penghargaan yang tiada terhingga kepada semua pihak yang telah membantu sehingga kegiatan pengabdian masyarakat ini dapat terlaksana dengan baik, khususnya kepada Lembaga Pengabdian kepada Masyarakat (LPkM) Universitas Muslim Indonesia atas bantuan dana hibah pengabdian dosen pemula yang telah diberikan dan kepada Kepala Puskesmas Parangloe beserta stafnya.

\section{REFERENSI}

American Diabetes Association. 2016. Standards of Medical Care in Diabetes-2016 Abridged for Primary Care Providers. Clinical Diabetes. 34(1):3-21. https://dx.doi.org/10.2337/diaclin.34.1.3

Cooke, D., Bond, R., Lawton, J., Rankin, D., Heller, S., Clark, M., Speight, J., U.K. NIHR DAFNE Study Group. 2013. Structured type 1 diabetes education delivered within routine care: impact on glycemic control and diabetesspecific quality of life. Diabetes Care. 36(2):270272. https://doi.org/10.2337/dc12-0080

Galicia-Garcia, U., Benito-Vicente, A., Jebari, S., LarreaSebal, A., Siddiqi, H., Uribe, K.B., Ostolaza, H., Martín, C. 2020. Pathophysiology of Type 2 Diabetes Mellitus. International Journal of Molecular Sciences. 21(17):6275. https://dx.doi.org/10.3390/ijms21176275

Gucciardi, E., Chan, V.W.S., Manuel, L., Sidani, S. 2013. A systematic literature review of diabetes selfmanagement education features to improve diabetes education in women of Black African/Caribbean and Hispanic/Latin American ethnicity. Patient Education and 
Counseling. 92(2):235-245. https://doi.org/10.1016/j.pec.2013.03.007

Hermanns, N., Schmitt, A., Gahr, A., Herder, C., Nowotny, B., Roden, M., Ohmann, C., Kruse, J., Haak, T., Kulzer, B. 2015. The effect of a Diabetes-Specific Cognitive Behavioral Treatment Program (DIAMOS) for patients with diabetes and subclinical depression: results of a randomized controlled trial. Diabetes Care. 38(4):551-560. https://doi.org/10.2337/dc14-1416

International Diabetes Federation. 2018. IDF Western Pacific members: Indonesia. https://www.idf.org/our-network/regionsmembers/western-pacific/members/104indonesia.html

Kementerian Kesehatan Republik Indonesia. Riset Kesehatan Dasar 2018. Jakarta: Kementerian Kesehatan Republik Indonesia. http://www.depkes.go.id/resources/downl oad/general/Hasil\%20Riskesdas\%202018.pd $\mathrm{f}$

Perkumpulan Endokrinologi Indonesia. 2015. Konsensus Pengelolaan dan Pencegahan Diabetes Melitus Tipe 2 di Indonesia 2015. Jakarta: Perkumpulan Endokrinologi Indonesia

Powers, M.A., Bardsley, J., Cypress, M., Duker, P., Funnell, M.M., Fischl, A.H., Maryniuk, M.D., Siminerio, L., Vivian, E. 2016. Diabetes Selfmanagement Education and Support in Type 2 Diabetes: A Joint Position Statement of the American Diabetes Association, the American Association of Diabetes Educators, and the Academy of Nutrition and Dietetics. Clinical Diabetes. 34(2):70-80. https://dx.doi.org/10.2337/diaclin.34.2.70

Sugiyama, T., Steers, W.N., Wenger, N.S., Duru, O.K., Mangione, C.M. 2015. Effect of a communitybased diabetes self-management empowerment program on mental healthrelated quality of life: a causal mediation analysis from a randomized controlled trial. BMC Health Services Research. 15:115. https://dx.doi.org/10.1186/s12913-015-07792

Tang, P.C., Overhage, J.M., Chan, A.S., Brown, N.L., Aghighi, B., Entwistle, M.P., Hui, S.L., Hyde, S.M., Klieman, L.H., Mitchell, C.J., Perkins, A.J., Qureshi, L.S., Waltimyer, T.A., Winters, L.J.,
Young, C.Y. 2013. Online disease management of diabetes: engaging and motivating patients online with enhanced resources-diabetes (EMPOWER-D), a randomized controlled trial. Journal of the American Medical Informatics Association. 20(3):526-534. https://doi.org/10.1136/amiajnl-2012-001263 